Editorial

\title{
Forming Processes of Modern Metallic Materials
}

\author{
Tomasz Trzepieciński ${ }^{D}$
}

Department of Materials Forming and Processing, Rzeszow University of Technology, al. Powst. Warszawy 8, 35-959 Rzeszów, Poland; tomtrz@prz.edu.pl; Tel.: +48-17743-2527

Received: 2 July 2020; Accepted: 16 July 2020; Published: 18 July 2020

\section{Introduction and Scope}

The plastic working of metallic materials is one of the most efficient and important manufacturing technologies used in industry today. Lightweight materials, such as titanium alloys, aluminium alloys, and ultra-high-strength steels are used extensively in the automotive, aerospace, transportation, and construction industries, leading to increasing demand for advanced innovative forming technologies. Numerical simulation is currently highly focused and provides a better understanding of innovative forming processes. Computational methods and numerical analysis, coupled with the modelling of structural change, allow us to reduce the time taken and eliminate experimental tests. The aim of this Special Issue is to present the latest achievements in various modern metal forming processes and the latest research related to the computational methods used for metal forming technologies. Research articles focusing on new developments in the forming of metallic materials are welcome for consideration for publication. I truly believe that this Special Issue will help the metals research community enhance their understanding of the present status and trends of the forming processes of modern metallic materials.

The modernisation of methods of plastic forming and the development of new techniques is mainly conditioned by the provision of innovative processing methods for shaping new types of materials, primarily in the automotive and aircraft industries. In parallel, a comprehensive approach is required to reduce the consumption of energy and materials in the context of the implementation of systems linked to the fourth industrial revolution (Industry 4.0). The search for high-performance unconventional methods of plastic working is reflected in the topics of the articles published in this Special Issue.

\section{Contributions}

Two review articles and ten research papers have been published in this Special Issue of Metals. The subjects are multidisciplinary, including (i) friction and lubrication in sheet metal forming (SPF), (ii) hot strip rolling and tandem strip rolling, (iii) application of numerical methods to simulate metal forming processes, (iv) development of new creep performance materials, (v) the Single Point Incremental Forming (SPIF) process, and (vi) the fatigue fracture characteristics of Alclad 7075-T6 aluminium alloy sheets joined by refill friction stir spot welding (RFSSW).

Firstly, two articles summarise the approaches on the innovative numerical algorithms, experimental methods, and theoretical contributions that have recently been proposed for SMF by researchers and business research centres. In the paper by Trzepiecinski and Lemu [1], the methods used to represent the friction conditions in conventional SMF and incremental sheet forming (ISF) have been summarised. Furthermore, the main disadvantages and limitations of the modelling methods of friction phenomena in specific areas of the material to be formed have been discussed. It has been concluded that although most of the friction tests were developed many decades ago, they are still valid and used by many authors. Although the methods to determine friction resistance in conventional SMF at different temperature conditions have been fairly well understood, there are a 
very limited number of experimental tests modelling conditions in ISF. This is due to the difficulty in separating the frictional resistance from the plastic deformation resistance in the process. The article of Trzepieciński [2] is intended to summarise recent development trends in both the numerical and experimental fields of conventional deep-drawing, spinning, flexible-die forming, electromagnetic forming, and computer-controlled forming methods, like incremental sheet forming. The review is limited to the considerable changes that have occurred in the SMF sector in the last decade, with special attention given to the 2015-2020 period. The progress observed in the last decade in the area of SMF mainly concerns the development of nonconventional methods of forming difficult-to-form lightweight materials for automotive and aircraft applications. In evaluating the ecological convenience of SMF processes, the tribological aspects have also become the subject of great attention.

Secondly, the modelling of tribological phenomena in SMF was discussed in three articles. Thus, one objective of the work reported in the paper by Trzepiecinski and Lemu [3] was to better understand the contact pressure acting on the rounded edge of the cylindrical counter-sample in the bending under tension (BUT) test by assuming the anisotropic properties of the metallic sheet. Another objective of this article was to calculate the coefficient of friction (COF) that acts during the BUT test for different strains of sheet metal. It was found that the effectiveness of the lubrication depends on the balance between two mechanisms accompanied by the friction process: roughening of workpiece asperities and adhesion of the contacting surfaces. The used lubricants were able to reduce the value of the friction coefficient approximately by $3-52 \%$ in relation to the surface roughness of the rolls. Trzepiecinski and Fejkiel [4] carried out both experimental and numerical finite element method-based studies of the frictional phenomena and material deformation during the flow of sheet metal through a drawbead. Different set-up conditions, including drawbead height and specimen widths, have been considered. Tribological tests have been carried out on DC04 steel sheets commonly used in the automotive industry using a special tribological drawbead simulator. Trzepiecinski [5] has compared the tribological properties of a deep drawing quality steel sheet using the three commonly used friction tests, i.e., the strip drawing test, draw bead test, and bending under tension test. Friction tests have been conducted under different pressure and lubrication conditions, surface roughness of tools represented by counter-samples, and orientations of the specimens according to the direction of the sheet rolling. The effectiveness of the reduction in the coefficient of friction by the lubricant clearly depended on the specimen orientation and surface roughness of the counter-samples. Differences in the coefficient of friction obtained from various tribological tests indicate a strong dependence of the kinematic conditions of the process on parameters directly related to the characteristics of the friction process.

Thirdly, the analysis of the rolling process was discussed in three articles. Li et al. [6] provided the basic principles of the six models; they verified the predictability of the bending force using these models based on a real-life dataset of a $1580-\mathrm{mm}$ hot rolling process in a steel factory. In this paper, six machine learning models, including Artificial Neural Network (ANN), Support Vector Machine (SVR), Classification and Regression Tree (CART), Bagging Regression Tree (BRT), Least Absolute Shrinkage and Selection operator (LASSO), and Gaussian Process Regression (GPR), were applied to predict the bending force in the hot strip rolling (HSR) process. A comparative experiment was carried out based on a real-life dataset, and the predicted performance of the six models was analysed on the basis of prediction accuracy, stability, and computational cost. The results show that the Gaussian process regression model is considered the optimal model for the prediction of bending force with the best prediction accuracy, better stability, and acceptable computational cost. Kraner et al. [7] studied the influence of asymmetric rolling in comparison with symmetric rolling, with respect to the technological, mechanical, and metallographic perspectives. The interactions between the measured rolling forces, the achieved strains, the tensile and yield strength, the hardness, the indicators of planar anisotropy, the microstructures with an average size of grains and crystallographic textures with volume fractions of different rolling, shear, and recrystallization texture components were investigated. The impact of asymmetric cold rolling was quantitatively assessed for an industrial 5754 aluminium 
alloy. The main advantage of asymmetric rolling is the presence of significant shear strain, leading to a gradient structure. It was found that the increased isotropy of the deformed and annealed aluminium sheet is a product of the texture heterogeneity and reduced volume fractions of the separate texture components. Mao et al. [8] proposed tandem skew rolling (TSR) for the production of seamless tubes. In order to study the deformation characteristics and mechanism on tubes obtained by the TSR process, a numerical simulation of the process was analysed using Deform-3D software. Based on numerical analysis, experiments were carried out with carbon steel 1045, high-strength steel (HSS) 42CrMo, and magnesium alloy AZ31 on the TSR testing mill to verify the feasibility of the process. Based on the studies carried out, it was found that rolling on a TSR testing mill allowed TSR to be run with high efficiency in the deformation of seamless tubes pierced and rolled at the same time, which makes continuous skew rolling more economical and practical.

Fourthly, as far as electromagnetic forming (EMF) is concerned, Cui et al. [9] established a three-dimensional (3D) finite element model (FEM), including quasi-static stamping, sequential coupling for electromagnetic forming (EMF), and springback, to analyse springback calibration by electromagnetic force. It was found that the tangential stress in the sheet bending region is reduced, and even the direction of tangential stress in the bending region is changed after EMF. Forming with a higher discharge voltage significantly reduced the springback phenomenon.

Fifthly, the development of new materials with good creep performance is a topic of the paper of Heo et al. [10]. A modified 9Cr-2W (alloy B) steel was developed in this study for use as fuel cladding with good creep performance for sodium-cooled fast reactors. The causes of fracture during the manufacturing process of alloy $B$ steels with low production yield were investigated in order to develop a novel manufacturing process for alloy B steels with high formability.

Sixthly, the dimensional accuracy and mechanical properties of metal components formed by SPIF have been extensively studied by Slota et al. [11]. An X-ray diffraction method has been applied to achieve an understanding of the residual stress formation caused by the SPIF process on DC04 steel sheet drawpieces. It was found that step size had a very large impact on the value of residual stresses. An increase in step size causes an increase in the absolute values of axial and tangential residual stresses. X-ray analysis of the walls of truncated cones led to the conclusion that residual stresses measured in a tangential direction decrease with increasing values of the surface roughness parameters Sa and Sq.

Finally, Kubit et al. [12] have shown that the RFSSW technique has great potential to be a replacement for single-lap joining techniques such as riveting or resistance spot welding used in the aircraft industry. The RFSSW technique is used to join Alclad 7075-T6 aluminium alloy plates in a single-lap configuration, which were subjected to a high-cycle fatigue test. Paris' law for crack propagation has been successfully adopted to predict the fatigue crack growth of lap-shear RFSSW specimens. Although some assumptions have been made, the comparison of the analytical and experimental fatigue crack growth rate confirms the potential of Paris' law to analyse the crack growth in RFSSW joints.

\section{Conclusions and Outlook}

The emergence of new plastic forming methods forces the modernisation of the existing machine park and the economically justified implementation of automation systems and robotisation of the machining process. In the SMF area, there is a tendency to adapt machines for flexible production, as well as to improve material flow through the production lines. Striving to improve the functionality of machines and extend the period of their trouble-free operation are the most important challenges facing the creators and propagators of the concept of the so called fourth industrial revolution (Industry 4.0). The implementation of this concept creates an increased demand for innovation in the field of new materials and technologies, which are one of the leading topics presented in this Special Issue.

As guest editor of this Special Issue, I am very happy with the final result and hope that the papers presented will be useful to academic researchers and industrial designers working in the plastic 
working of metallic materials sector. I also hope that all the scientific results in this Special Issue will contribute to the future development of research on the plastic working of metallic materials. I would like to thank all the authors for their contributions and all of the anonymous reviewers who assisted me in the reviewing process. I would also like to give special thanks to staff at the Metals Editorial Office, especially to Ms. Betty Jin, Assistant Editor, who managed and facilitated this Special Issue.

Conflicts of Interest: The author declares no conflicts of interest.

\section{References}

1. Trzepiecinski, T.; Lemu, H.G. Recent Developments and Trends in the Friction Testing for Conventional Sheet Metal Forming and Incremental Sheet Forming. Metals 2020, 10, 47. [CrossRef]

2. Trzepieciński, T. Recent Developments and Trends in Sheet Metal Forming. Metals 2020, 10, 779. [CrossRef]

3. Trzepiecinski, T.; Lemu, H.G. Effect of Lubrication on Friction in Bending under Tension Test-Experimental and Numerical Approach. Metals 2020, 10, 544. [CrossRef]

4. Trzepiecinski, T.; Fejkiel, R. A 3D FEM-Based Numerical Analysis of the Sheet Metal Strip Flowing Through Drawbead Simulator. Metals 2020, 10, 45. [CrossRef]

5. Trzepiecinski, T. A Study of the Coefficient of Friction in Steel Sheets Forming. Metals 2019, 9, 988. [CrossRef]

6. Li, X.; Luan, F.; Wu, Y. A Comparative Assessment of Six Machine Learning Models for Prediction of Bending Force in Hot Strip Rolling Process. Metals 2020, 10, 685. [CrossRef]

7. Kraner, J.; Fajfar, P.; Palkowski, H.; Kugler, G.; Godec, M.; Paulin, I. Microstructure and Texture Evolution with Relation to Mechanical Properties of Compared Symmetrically and Asymmetrically Cold Rolled Aluminum Alloy. Metals 2020, 10, 156. [CrossRef]

8. Mao, F.; Wang, F.; Shuang, Y.; Hu, J.; Chen, J. Deformation Behavior and Experiments on a Light Alloy Seamless Tube via a Tandem Skew Rolling Process. Metals 2020, 10, 59. [CrossRef]

9. Cui, X.; Zhang, Z.; Yu, H.; Xiao, X.; Cheng, Y. Springback Calibration of a U-Shaped Electromagnetic Impulse Forming Process. Metals 2019, 9, 603. [CrossRef]

10. Heo, H.M.; Kim, J.H.; Kim, S.H.; Kim, J.R.; Moon, W.J. Influence of Heat Treatment on the Workability of Modified 9Cr-2W Steel with Higher B Content. Metals 2019, 9, 904. [CrossRef]

11. Slota, J.; Krasowski, B.; Kubit, A.; Trzepiecinski, T.; Bochnowski, W.; Dudek, K.; Neslušan, M. Residual Stresses and Surface Roughness Analysis of Truncated Cones of Steel Sheet Made by Single Point Incremental Forming. Metals 2020, 10, 237. [CrossRef]

12. Kubit, A.; Drabczyk, M.; Trzepiecinski, T.; Bochnowski, W.; Kaščák, L'; Slota, J. Fatigue Life Assessment of Refill Friction Stir Spot Welded Alclad 7075-T6 Aluminium Alloy Joints. Metals 2020, 10, 633. [CrossRef]

(C) 2020 by the author. Licensee MDPI, Basel, Switzerland. This article is an open access article distributed under the terms and conditions of the Creative Commons Attribution (CC BY) license (http://creativecommons.org/licenses/by/4.0/). 